\title{
Prolonged neonatal jaundice
}

\author{
Antonietta Giannattasio, Giusy Ranucci, Francesco Raimondi ${ }^{*}$ \\ From 71st Congress of the Italian Society of Pediatrics. Joint National Meeting SIP, SIMGePeD, Study Group \\ on Pediatric Ultrasound, SUP Study Group on Hypertension \\ Rome, Italy. 4-6 June 2015
}

Prolonged neonatal jaundice is defined as a jaundice lasting more than 14 days of life in the full-term infants $[1,2]$. Etiologically it is helpful to distinguish jaundice related to unconjugated (indirect) or conjugated (direct) hyperbilirubinemia. A prolonged unconjugated hyperbilirubinemia may be related to breastfeeding or to some pathological conditions as hemolytic diseases (due to Rh or AB0 incompatibility, or G6PD deficiency), congenital hypothyroidism, urinary infection, Crigler-Najjar or Gilbert syndromes $[1,2]$. Conjugated hyperbilirubinemia (cholestatic jaundice) is never physiologic. It affects $1 / 2500$ live births and it should be suspected in all jaundiced infants with light stools and dark urine [3,4]. Delayed referral of cholestatic neonates is still a significant problem. To promote early diagnosis of cholestasis, it is recommended that any infant who remains jaundiced beyond age 2 to 3 weeks (for breastfed infants who can be monitored and who have an otherwise normal history and physical examination) should have the serum bilirubin level fractionated [5].

The differential diagnosis of cholestasis is extensive, and early recognition is essential to ensure timely treatment and optimal prognosis [6]. Developments in molecular genetic techniques have enabled the identification of causative genes, which has improved diagnostic accuracy for patients [7].

In case of neonatal cholestasis, the first step should be the assessment of coagulation and urgent parenteral vitamin $\mathrm{K}$ administration in case of coagulopathy and the exclusion of life-threatening conditions or disorders requiring urgent specific medical (eg. NTBC in tyrosinemia, elimination diet in galactosemia and ereditary fructose intolerance) and surgery treatment. Biliary atresia is the most frequent single cause of neonatal cholestasis and affected infants appear otherwise healthy and grow normally [8]. Early performance of a hepatoportoenterostomy in the first 45 days of

\footnotetext{
*Correspondence: raimondi@unina.it

Department of Translational Medical Science-Section of Neonatology,
} University Federico II, Naples, Italy

(c) 2015 Giannattasio et al. This is an Open Access article distributed under the terms of the Creative Commons Attribution License (http://creativecommons.org/licenses/by/4.0), which permits unrestricted use, distribution, and reproduction in any medium, provided the original work is properly cited. The Creative Commons Public Domain Dedication waiver (http://creativecommons.org/ publicdomain/zero/1.0/) applies to the data made available in this article, unless otherwise stated. life to restore bile flow and lessen further damage to the liver is thought to optimize outcome [9].

Infants admitted in NICUs have a rate of cholestasis higher than that reported in the general population of live births; in most cases, cholestasis is associated to multiple risk factors and shows a favorable outcome [10].

Long-term cholestasis determines malnutrition, psychomotor development delayed and immune deficiency. So that even when specific treatment is not available, infants who have cholestasis benefit from early medical management and nutritional support for malabsorption and vitamin deficiency [8].

\section{Published: 30 September 2015}

\section{References}

1. American Academy of Pediatrics: Management of hyperbilirubinemia in the newborn infant 35 or more weeks of gestation. Pediatrics 2004, 114:297-316.

2. Maisels MJ, Bhutani VK, Bogen D, Newman TB, Stark AR, Watchko JF: Hyperbilirubinemia in the newborn infant 35 weeks' gestation: an update with clarifications. Pediatrics 2009, 124:1193-1198.

3. Mc Kiernan P: Neonatal jaundice. Clin Res Hepathol Gastroenterol 2012, 36:252-256.

4. Feldman AG, Sokol RJ: Neonatal cholestasis. Neoreviews 2013, 14.

5. Moyer V, Freese DK, Whitington PF: Guideline for the evaluation of cholestastic jaundice in infants: recommendations of the North American Society for Pediatric Gastroenterology, Hepatology and Nutrition. J Pediatr Gastroenterol Nutr 2004, 39:1115-128.

6. Venigalla S, Gourley GR: Neonatal cholestasis. Semin Perinatol 2004, 28:348-55.

7. Hartley $\mathrm{J}$, Gissen $P$, Kelly DA: Alagille syndrome and other hereditary causes of cholestasis. Clin Liver Dis 2013, 17:279-300.

8. De Bruyne R, Van Biervliet S, Vande Velde S, Van Winckel M: Clinical practice: neonatal cholestasis. Eur J Pediatr 2011, 170:279-84.

9. Khalil BA, Perera MT, Mirza DF: Clinical practice: management of biliary atresia. Eur J Pediatr 2010, 169:395-402.

10. Tufano M, Nicastro E, Giliberti P, Vegnente A, Raimondi F, lorio R: Cholestastis in neonatal intensive care units; incidence, etiology and management. Acta Pediatr 2009, 98:1756-1761.

doi:10.1186/1824-7288-41-S2-A36

Cite this article as: Giannattasio et al:: Prolonged neonatal jaundice. Italian Journal of Pediatrics 2015 41(Suppl 2):A36. 